\title{
COLONIZACIÓN DE LA NATURALEZA: UNA APROXIMACIÓN DESDE EL EXTRACTIVISMO EN COLOMBIA.
}

\author{
COLONIZATION OF NATURE: \\ AN APPROACH FROM EXTRACTIVISM IN COLOMBIA. \\ Recibido: enero de 2012 - Revisado: junio de 2012 - Aceptado: 30 de noviembre de 2012
}

Por: Luis Alfredo Bohórquez Caldera. ${ }^{1}$

\section{RESUMEN:}

Este artículo de investigación pretende brindar elementos de análisis sobre el complejo tema de la colonización de la naturaleza. En él se hace una argumentación descriptiva basada hallazgos teóricos sobre las relaciones entre el extractivismo, una práctica propia del dispositivo colonial, y lo que aquí denominamos colonización de la naturaleza. El artículo presenta inicialmente un balance del impacto en la configuración de la visión-apropiación ancestral del territorio y su contenido cultural, a raíz de la imposición de una nueva semántica, en referencia al dispositivo de poder colonial. Luego, se analiza la relación del extractivismo con el proceso de colonización de la naturaleza, para finalmente esbozar una reflexión breve vinculando contextos y problemas contemporáneos.

\section{PALABRAS CLAVES:}

Naturaleza, Mítica, Pensamiento ancestral, Extractivismo, Colonialidad.

\section{ABSTRACT:}

This research paper aims at providing some elements of analysis on the complex issue of the colonization of nature. In it a descriptive argument is carried out based on theoretical findings on the relationships between extractivism, which is a proper practice of the colonial device, and what is here called colonization of nature. The article initially presents an assessment of the impact on the configuration of the ancestral vision and appropriation of the territory and its cultural contents, as a result of the imposition of a new semantics, in reference to the device of the colonial powers. Then, the relationship between extractivism and the process of colonization of nature is analyzed; to finally sketch a brief reflection, by linking contemporary issues and contexts.

\section{KEY WORDS AND EXPRESSIONS:}

Nature, mythical, ancient thinking, extractivism, coloniality.

\footnotetext{
${ }^{1}$ Licenciado en Teologia, Especialista en pedagogía y docencia universidad, Magister en Bioética, Estudiante del Doctorado en Educación y Cultura en la Universidad Arcis, Santiago de Chile. Docente Investigador Universidad de San Buenaventura Bogotá - Colombia. Luis.bohorquez@usbbog.edu.co.
} 


\section{Introducción.}

El presente artículo propone realizar un análisis del proceso de colonización de la naturaleza y el papel que juega el extractivismo en este proceso. Haremos referencia la naturaleza entendiendo que ella es el cúmulo de elementos biológicos, sus características, las narrativas, las visiones, los simbolismos y las cosmovisiones a través de las cuales se hace lectura, explicación, comprensión y praxis de lo que identificamos como "la cosa natural". La naturaleza vista como realidad apropiada culturalmente por una comunidad humana.

Naturaleza, extractivismo y colonialidad, Tres ideas para analizar la colonización de la naturaleza en perspectiva crítica y contemporánea, elementos funcionales del dispositivo colonial. En esta medida, se parte de la premisa que el extractivismo es una forma de colonización de la naturaleza y por tanto, constituye un elementos clave en el dispositivo de poder colonial que se estableció en Colombia y en América Latina con la llegada de los conquistadores europeos y que hoy se ha disfrazado de modelo de desarrollo económico, que temina favoreciendo un modelo que empobrece y desplaza a comunidades rurales que carecen de los medios y los mecanismos para hacer frente al poder hegemónico de grupos económicos que ejercen control sobre territorios, riquezas naturales y proyectos de gran infraestructura en el campo de la minería.

No ha habido muchos cambios en la aplicación del modelo extractivista, la lógica es quizá la misma: un modelo rentista y depredador; entre lo que otrora hizo el colonizador español, y lo que hoy hacen las transnacionales que ostentan el control de los bienes-recursos naturales de la geografia colombiana, no hay mucha diferencia. Tal situación, bien puede catalogarse como una "hecatombe" social.

El extractivismo ha jugado y en la actualidad juega un rol de vital importancia. Porque el extractivismo se camufló en las políticas sociales y en el discurso gobiernista sobre el desarrollo social.

El extractivismo, según Gudinas (2009):

Es una de las banderas de los gobiernos progresistas en América Latina. Según él, a pesar de los profundos cambios políticos continentales hacia la izquierda, los sectores extractivistas mantienen su importancia y son uno de los pilares de las estrategias de desarrollo actuales. (p. 188).

De tal forma, que se puede entender que los proyectos y megaproyectos relacionados con extractivismo en el área de la minería, no son otra cosa que el (neo) extractivismo disfrazado de una prosperidad falaz en la que por ejemplo, la política de restitución de tierras en Colombia, a la fecha en la que se escribe este texto, no ha restituido una sola hectárea de tierra a los campesinos. El desarrollo social, dícese de la prosperidad económica, se plantea en atención a los intereses y a la posición dominante de las trasnacionales que controlan la geopolitica de este país.

El extractivismo se estableció como mecanismo de depredación de los bienes-recursos naturales con la llegada de Gonzalo Jiménez de Quesada y el resto de las huestes españolas a las tierras de Bacatá, Suamox, Hunza, Panches, Coyaimas Quimbayas, Caribes y en general, en los territorios colonizados. Por su imbricación con la naturaleza y con la población, puede 
ser visto como una práctica colonial porque el establecimiento de poderes hegemónicos desembocó en prácticas de un modelo de economía basado en el rentismo y el extrativismo, que sin duda hoy, lo mismo que ayer, tiene que ver con los niveles de exclusión de la población rural campesina en Colombia, con el empobrecimiento de la misma, con la vulneración de derechos humanos y con la contaminación y deterioro del ambiente en las zonas de desarrollo de proyectos mineros y de extracción masiva de bienes-recursos naturales.

La modificación de las relaciones humano-naturaleza producto de la imposición del sistemamundo colonial.

Con la llegada del conquistador según narran los cronistas de indias, entre ellos Fray Pedro Simón, Juan de Castellanos, Juan Rodríguez Freire y Gonzalo Jiménez de Quesada, se gestaron grandes rupturas entre el modus vivendi de las comunidades amerindias y sobre todo, se dio inició a un plan de destrucción y desplazamiento de las expresiones y representaciones míticas a través de las cuales las comunidades precolombinas vivenciaban las relaciones humano-naturaleza.

Según Bohórquez (2009), "los mitos y los ritos formaban parte de la cotidianidad de los pueblos (precolombinos), y expresaban el sentido y el simbolismo de su pensamiento en relación con aquellas cosas que consideraban en su geografia como sagradas" (p. 157), por ejemplo, la naturaleza. Además, en estos pueblos, la historia mítica ${ }^{2}$ estructuró y codificó un tipo experiencia relacional humano-naturaleza, dando como resultado, comunidades agrarias, cazadores y orfebres, con fuerte influencia-dependencia de su hábitat o entorno natural.

Narra Gonzalo Jiménez de Quesada en el Epítome de la Conquista del Nuevo Reino de Granada, refiriéndose al deseo de riquezas que traían los españoles, que "después que pasaron las tierra, en una tierra que nombró San Gregorio. Diéornle ciertas esmeraldas. Preguntó el licenciado a los indios de donde las avían y fuese al rastro de ellas. ... y le dixo por unos indios como las esmeraldas que buscava estavan en tierras y señorío del rey Tunja." (Ramos, 1972. p, 286-287) En este fragmento del Epítome, que es uno de los escritos más antiguos en los que se narra la llegada de los españoles a las tierras colombianas, ya se evidencia la intención de aplicar el extractivismo como modelo de economía. El conquistador tenía aprehendido métodos extrativistas y vio necesario aplicarlos para obtener las riquezas de estas tierras y así, ejercer el control colonial.

Sobre el mismo aspecto (la introducción del extractivismo a través de las formas de economía colonial), se pueden ampliar detalles usando como fuentes a Fray Pedro Simón (1625), Lucas Fernández de Piedrahita (1668), Juan Rodríguez Freire (1963), Miguel Triana (1922), Liborio Zerda (1883), Ramos (1972), Hernández (1975), Beltrán (1976), y Bohórquez (2009). En general, lo que se abstrae de los textos son evidencias que confirman las maneras como operó la empresa colonial en la transformación de las relaciones humano-naturaleza. Dicha empresa, generó una ruptura cultural, en la medida en que se modificaron los hábitos de producción y de consumo de los pueblos antiguos. Y se desplazó la cosmovisión natural de la geografia que hacía parte de la historia y del tiempo mítico. Historia y tiempo mítico se transformaron sistemáticamente por la cosmovisión colonial. Y dio origen a una nueva semántica y una nueva semiótica sobre la naturaleza: la de los bienes-recursos naturales y su funcionalidad económica, la cual, fue orientada lógicamente hacia la satisfacción de las necesidades del poder imperialista. 
También se transformó la razón de ser y las características de relación entre el humano y la naturaleza. Porque el "indio" que se sostenía del usufructo de sus artes agrarios y orfebres, se desligó de sus obligaciones en relación con el clan y con las deidades, y contrajo deudas con la corona y con sus representantes en etas tierras. Deudas que se pagaban con trabajo y en especies, incluyendo personas. Fue así como los pagamentos y las ofrendas cambiaron de destinatario. Precisamente porque el dispositivo de poder colonial al imponer sus leyes y sus costumbres, fortaleció a la corona española en su propósito de civilizar y evangelizar estas tierras.

La modificación en la relación humano-naturaleza tuvo lugar en la medida en que la ritualidad que involucraba en primera instancia a la naturaleza, fue paulatinamente desplazada por el influjo del cristianismo católico. Es decir, por el impacto del adoctrinamiento religioso.

El moque y la trementina que se quemaban durante los pagamentos indigenas se cambiaron por el incensario y por el agua bendita para los bautismos y los rituales sacramentales católicos. Los sacrificios de moxas, jóvenes que se degollaban a las deidades en ceremoniales especiales, se sustituyó por la inmolación del cordero eucarístico en los altares católicos. El sonido de quenas y fotutos, se cambió por los cantos en latín del Kirie eleison y el Regina Coeli, y el rezo de la misa canónica según el rito romano.

Hasta la llegada de los colonizadores, la vida de los pueblos precolombinos giraba en torno a rituales y a simbolismos de carácter mítico. Tanto los rituales como los simbolismos fueron construidos alrededor de la vivencia relacional con el medio geográfico natural. La famosa leyenda del Dorado que según Simón, entronizaba en el poder a los caciques en su cacicazgo, los ritos y pagamentos en torno a Sié, la diosa agua, que se hacían en los espejos lagunares de Guatafita, Siecha, Tota, Fúquene, y también en algunos arroyos; los ritos a las divinidades tutelares como Cuchaviva, Bochica, a Quemuenchatocha, Chié, Chiminigagua, representaban la relación con la tierra, con las lagunas, con el paisaje, con las creencias nutricias de la cultura. Toda esta parafernalia mítica se sustituyó por un cambio radical en las actividades cotidianas de los indios. El trabajo agrario y orfebre empezó a tener un fin comercial. La extracción de minerales, de metales preciosos y los maderables, se orientó a sufragar gastos y necesidades de la corona española y de la iglesia.

Como afirma Bohórquez (2008), "la naturaleza hacía parte de una representación mítica "sacra" de los pueblos antiguos" (p. 157-160). La cual, con la llegada de los conquistadores, con el radicalismo, el cristianismo, el latín, la lengua hispana, en fin, con la llegada del imperio español, los intangibles culturales se destruyen. Mueren porque el colonizador instauró en el imaginario social la necesidad de comerciar y de reunir riquezas y esto hizo que el indio se desligara del bien natural, aunque persistía en su arraigo por la tierra desde la ritualidad mítica. Esta ritualidad natural fue el móvil de execrables castigos por parte del dispositivo colonial que se ejerció desde la cristiandad. En las Heterogamias de la mítica indígena, la idea de naturaleza corresponde a la idea de "Tierra generatrix", "muter erde" según Eliade (1961), "matriz subterránea, vientre húmedo, la misma que según sus creencias ancestrales se sostenía sobre maderos sagrados en brazos de la deidad Cuchavira o Cuchaviva" (Bohórquez, 2008, p. 157-160).

El cronista encontró a su llegada culturas mayoritariamente ágrafas. Por eso le fue necesario narrar las cosmogonías y las antropogonías de los indios, no desde el arquetipo ancestral (porque todavía no comprendía la lengua de los indios) sino desde la enunciación epistémica 
europea, desde la semántica latina y castellana. Y Desde la pre comprensión teológica y religiosa del mundo, del hombre y de la naturaleza. Esto contribuyó en el proceso de extinción de la mítica natural, y facilitó la occidentalización del pensamiento ecológico primitivo, y dio permisos para instaurar procesos de persecución a la ritualidad con la tierra. Entonces surgieron por necesidad, procesos de adaptación y de aculturación que condujeron a que los pueblos antiguos abandonen su condición de habitantes naturales de la tierra, y bajo pena de castigo, dejaron a un lado sus creencias, las que habian construido desde el simbolismo del mito y el legado ancestral. Las que explicaban sus creencias y sus tradiciones orales en su longeva ritualidad. Una ritualidad celebrativa donde predominaba la mimesis y no el dualismo occidental de lo sacro y lo profano. Es decir, hubo un cambio de mentalidad. Y este se reafirma cuando el indio pasó a ser siervo de la gleba, cuando fue confinado en doctrinas y en feudos según el modelo de la Europa medieval.

Una vez fue impuesto el dispositivo colonial, desapareció entre los indios la posibilidad de retorno a sus costumbres nativas y ancestrales. Allí, no solo se transformó el paisaje a usanza del poder hispano, sino que se inició el proceso de blanqueamiento de la cultura.

Cuando se introdujo una nueva visión sobre la naturaleza, emergieron entre los indios hábitos de consumo distintos. Desde la mirada veterotestamentaria del hombre como señor y dominador de la naturaleza, impuesta por el modelo evangelizador eclesiástico, las ofrendas a las deidades pasaron a ser las canteras de los tesoros que codiciaba el colonizador. Se inició entonces el extractivismo como una empresa incipiente que va tomado cada vez más fuerza, pues, se fueron abriendo poco a poco rutas comerciales, y la corona dispuso entregas a diestra y siniestra de títulos de apropiación y explotación de tierras. Todo esto fue posible también por la imposición de la idea de civilización, y luego fue la idea de cultura y consecuentemente la idea de desarrollo. Tres ideas poderosas traídas desde Europa. Estos conceptos fueron desde el inicio estructuralmente soporte del dispositivo colonial. Según Mignollo (2003), la implementación del colonialismo, significó "integrar" distintos pueblos a las ideologías de la modernidad europea. La ideología colonialista homogeneizó las culturas locales en torno a Europa como lugar de epistémico de enunciación. Esto facilitó la imposición de la idea de progreso mediante la falsificación del concepto civilización.

Para concluir esta parte, téngase en cuenta que la cuestión central, es decir, el término naturaleza, ha tenido siempre un uso complejo. Esto, porque el término tiene distintas "acepciones de acuerdo con los intereses políticos y económicos de distintos actores. Y se puede entender la naturaleza como espacio vital vivido y transformado por las culturas locales, y la naturaleza como mercancía, y la naturaleza como objeto de transformación tecnológica." (Escobar, 1999. p. 14).

\section{Metodologia.}

El presente artículo se sustenta en una argumentación descriptiva basada en hallazgos teóricos sobre las relaciones entre el extractivismo, una práctica propia del dispositivo colonial y lo que se denomina colonización de la naturaleza.

El artículo presenta inicialmente un balance del impacto en la configuración de la visiónapropiación ancestral del territorio y su contenido cultural, a raíz de la imposición de una nueva semántica, en referencia al dispositivo de poder colonial. 
Por último, se analiza la relación del extractivismo con el proceso de colonización de la naturaleza, para finalmente esbozar una reflexión breve vinculando contextos y problemas contemporáneos.

\section{Restultados - discusiones.}

Es un hecho que las relaciones humano-naturaleza cambiaron drásticamente en mundo Americano con la imposición del dispositivo colonial; éste cambio como se anotó en la introducción, se produjo por la aplicación del dispositivo colonial, y porque este, hizo migrar las interpretaciones y las construcciones míticas de la naturaleza hacia las cuestiones politicas y sobre todo económicas.

Es así que la naturaleza dejó de ser paisaje mítico, y se convirtió en potencial natural, en oportunidad de riquezas para los colonizadores hispanos. Y es desde allí desde donde el extractivismo empieza a regir como una forma de economía que funcionó porque se organizó la mano de obra disponible, gratuita entre otras cosas, se cartografiaron las tierras productivas y las especies naturales que se podían comercializar, para sobre ellas establecer una forma de economía que generara volúmenes cada vez mayores de materias primas que se enviaban al extranjero.

El extractivismo en perspectiva de dispositivo colonial.

El dispositivo colonial es la estrategia, la serie de circunstancias y mecanismos a través de los cuales ha sido posible establecer la colonialidad, no solo del poder, sino del ser y en general, la subaleternidad de la cultura. Según Mignollo (2003), "Quijano introduce el concepto colonialidad del poder, Dussel, el de transmodernidad, y ambos, buscan explicar la forma en la que el sistema-mundo-moderno, está siendo pensado desde otro extremo (un extremo otro)" (p. 114). En este sentido, el dispositivo de poder colonial se establece a través de la colonialidad, la modernidad y la posmodernidad, es decir, desde los presupuestos epistémicos europeos. Dicho establecimiento, se hizo de forma canónica, vertical y excluyente. Mignollo (2003), complementa esta visión cuando afirma que:

La modernidad y el colonialismo crean una estructuras de creencias de las que es necesario liberarse social y epistémicamente. La emancipación como liberación, significa no solo el reconocimiento de la condición subalterna, sino la eliminación de la estructura de poder que mantiene la hegemonía. (p. 90).

Desde este presupuesto, es donde se ubica el papel del extractivismo como un elemento estructural que hace posible, no solo la diferencia colonial sino la hegemonía del poder y la sublaternidad del "otro", que en el lenguaje colonial, es el "bárbaro". El dispositivo colonial funcionó como el criterio canónico para establecer la diferencia colonial teniendo como base el color de la piel, el lenguaje, la religiosidad, y las costumbres culturales.

Afirma Mignollo (2003), que:

La colonalidad del poder es el dispositivo que produce y reproduce la diferencia colonial. La diferencia colonial consiste en clasificar grupos de gentes e identificarlos por sus faltas o por sus excesos. Esta identificación se hace sobre la base de que quien identifica posee un rango cualitativo superior, según Las Casas, es no ser bárbaro. (Mignollo, 2003, p. 39). 
La colonialidad del poder operó como mecanismo clasificatorio. Por ello se afirma que la diferencia imperial sirvió para afianzar la mismidad y la diferencia de la cristiandad. Desde esta visión de las cosas, el extractivismo no solo responde a la imposición de la diferencia colonial, sino por esta misma imposición, los que fue diferenciados (como bárbaros) fueron simultáneamente marginado de las posibilidades sociales, del disfrute, del usufructo y del control de las riquezas representadas en bienes-recursos naturales. Desde la diferencia colonial, no solo se reprochó la conducta, las creencias y en general el modo de vida de los pueblos colonizados, sino que se les negó el derecho a poseer. Desde entonces, el título de extractar y explotar la economía de la tierra, quedó en manos de quienes ejercen el poder y el control desde el dispositivo colonial.

El dispositivo colonial es lo que permitió hacer las construcciones, las interpretaciones, los reconocimientos, y las apropiaciones epistémicas desde un "centro" como lugar de enunciación, generando lógicamente una "periferia". El dispositivo colonial es y será institucional. En este sentido representa indistintamente al poder, bien civil o eclesiástico. El dispositivo colonial es el lenguaje epistémico que interpretó y creó desde su propio imaginario-teorización la condición de subalternidad. El dispositivo colonial trajo consigo una ética y una estética, unas estructuras de comprensión, explicación y teorización de la verdad y del mundo, y en esta medida se comportó como un sistema de identificación cultural. El dispositivo colonial dispuso las grafias semánticas y las codificaciones lingüísticas para que el poder colonial hiciera lectura, interpretación y narración de los espacios y en general de las cartografias colonizadas.

Ahora bien, el dispositivo colonial no funciona solo. Necesita sustento. Necesita nutrirse de algo. Y es alli donde el extrativismo surge como una posibilidad de sustento de un modelo de colonialidad del poder. Por extractivismo se entiende en un sentido amplio "las actividades que remueven grandes volúmenes de recursos naturales, que no son procesados (o lo son limitadamente), y pasan a ser exportados" (Gudinas, 2009. 188-190). Además:

Se considera que el llamado extractivismo, que incluye la explotación minera y petrolera, tiene una larga historia en América Latina. A partir de esas actividades se han nutrido las corrientes exportadoras, que desempeñaron papeles claves en las economias nacionales, pero también han estado en el centro de fuertes polémicas por sus impactos económicos, sociales y ambientales. (p. 188).

Según Santiago Castro-Gómez (1998), en la perspectiva teórica de autores como Edward Said, Homi Bhabha y Gayatri Spivak:

El colonialismo no es algo que afecta únicamente a ciertos países, grupos sociales o individuos del "Tercer Mundo", sino una experiencia global compartida, que concierne tanto a los antiguos colonizadores como a los antiguos (o nuevos) colonizados. El colonialismo territorial y nacionalista de la modernidad ha desembocado en un colonialismo posmoderno, global y desterritorializado. (p. 155-182).

Se deduce de esta postura, que el extractivismo es una forma de colonialismo. No porque expresamente lo esté afirmando Castro-Gómez, sino porque es parte de la estructura de la colonialidad. Tanto el colonialismo como el extrativismo, hoy en día son una experiencia común en América Latina. El extractivismo como colonialismo territorial. 
Hofman (2001), afirma que: "Long-run empirical evidence shows that the availability of natural resources is not a decisive factor in economic development. There are examples of resource-rich countries that have grown rapidly over the long term while others have had only a modest economic performance. On the other hand there are examples of countries, despite being very poor in natural resources, that have grown at a spectacular pace”. (p. 1-28).

Lo primero que hay que decir es que nuestra posición en contraria a la Hofman (2001), porque en nuestro análisis partimos de la consideración de que la disponibilidad de recursos-bienes naturales si determinan el desarrollo económico. Y en este sentido, constituye un elemento estructural en el dispositivo de poder colonial. En Colombia, las comunidades primitivas condicionaron su modo de vida a la geografia. La naturaleza fue determinante culturalmente hablando. La experimentaron (Aprehendieron) como "hierofanía" (Beltrán,1976. p. 81). Esta reflexión se plantea para decir que desde una visión moderna, pensada en función de la geopolítica del sistema mundo-moderno colonial (Inmanuel Walerstein, 2001, Walter Mignollo, 2003, entre otros), que las afirmaciones de Hofman (2001) tienen sentido. Pero si se revisa con mayor detalle la historia económica de América Latina, no se puede desconocer que las riquezas naturales de estos territorios, se transformaron en riquezas coloniales para sociedades concretas que impusieron, no solo políticas de dominación, sino formas de aprovechamiento y usufructo de bienes que fueron apropiados-expropiados mediante el uso de la fuerza, y como dice Walerstein (2001), por la imposición de la idea de desarrollo. De donde se planta, que en estas formas de aprovechamiento de las riquezas naturales, el extractivismo es una constante en la historia económica de América Latina.

Hofman (2001), Shudt y Acosta (2006) concuerdan en que "justamente las economías dependientes de la extracción de recursos naturales no son las que más han crecido en las últimas décadas. Desde los años sesenta para acá, las economías subdesarrolladas primarioexportadoras dotadas con abundantes recursos naturales -en especial de los no renovableshan crecido a tasas menores por habitante que las que no disponen de ellos" (Shudt y Acosta, 2006, p. 10). Si este argumento es cierto, entonces las riquezas naturales de Brasil son despreciables en relación con su modelo y nivel de desarrollo social y económico. Y habría que preguntar ¿en que se sustenta entonces la industria de los países desarrollados? La respuesta puede ser que la naturaleza es el gran insumo de la industria a gran escala.

Lo que sucede es que en el debate sobre los costos ambientales del modelo de desarrollo capitalista y mercantilista, amparados en el extractivismo, se están naturalizado discursos, incluso discursos académicos, que buscan demostrar que los bienes-recursos naturales no son causa de riqueza. La pregunta entonces es ¿porqué persiste el interés de las multinacionales en controlar la geopolitica de los paises catalogados como Hot spot en biodiversidad?Shudt y Acosta (2006) interrogan a cerca de:

¿Cómo explicar esta curiosa contradicción entre la abundante riqueza natural y la pobreza en la gran mayoría de nuestros países? ¿Qué implicancias tiene para economías que dependen de la extracción de petróleo u otros minerales? ¿Es posible sobreponerse a los efectos negativos que ejerce la abundancia de recursos naturales? ¿Será inevitable repetir los fiascos que representaron las famosas bonanzas del petróleo y otras materias primas? (p. 10-15).

Sin duda estos interrogantes son claros y respetables. Lo que no quiere decir, que esta preguntas como parte de una retórica que responde a una geopolítica, esté empeñada en dar una respuesta fuera del marco de interpretación en el cual son planteadas: y el núcleo del 
asunto es simple: las países pobre son ricos en naturaleza, solo que no la pueden aprovechar para beneficio propio. ¿Por qué razón? Porque históricamente no se les ha reconocido esa autonomia, es decir, no son lo suficientemente adultos, democráticamente hablando, para hacerse cargo de sus propias riquezas, por lo cual, deben ser otros, quienes las exploten y se beneficien. Shudt y Acosta (2006), no advierten (porque su análisis es más económico que histórica cultural) que precisamente el dispositivo de poder colonial, ha impreso tanto control, que difícilmente los estados colonizados, han podido pensarse el desarrollo, fuera del circuito integrado del eurocentrismo y el norteamericanismo. Es decir, el desarrollo no ha resultado lo mismo en su modelo de aplicación, para los estados coloniales que para los estados colonizadores.

En la baraja de posibilidades que plantea del desarrollismo y el discurso progresista característico de los gobiernos actuales de América Latina, el occidentalismo, siempre ha sacado las mejores ventajas en términos de control geopolítico y macroeconómico. Recordemos que desde el siglo XIX, luego de que España y Portugal ceden es su postura hegemónica sobre América Latina, la geopolítica entra en disputa a través del comercio entre Inglaterra y Estados Unidos. Y desde entonces, ambas potencias se han encargado de hacer llegar hasta sus arcas, las riquezas provenientes del extractivismo aplicado a los recursos del continente americano. Por lo mismo, no es posible pensar que las potencias económicas modernas, deben su milagro económico, a un esfuerzo endógeno en donde el abastecimiento comercial externo no tuvo incidencia. Más bien, y se puede demostrar, la esclavitud, el vasallaje, la dependencia económica e intelectual, y el extractivismo rentista, han permitido el nivel de desarrollo de sociedades que a su vez, han propiciado el empobrecimiento de otras mediante diversos mecanismo de control y de poder. Porque precisamente el extractivismo beneficia sólo al destinatario de los bienes, no a los habitantes del territorio donde se encuentran las riquezas. Verbigracia, los contratos y concesiones sobre minería en cualquier país latinoamericano.

En decir, el extractivismo, como parte del dispositivo colonial, ha funcionado de manera eficiente, $\mathrm{y}$ ha generado riquezas para quienes ejercen el control comercial, desde que fue impuesto por el colonialismo hispano-portugués hasta nuestros dias. Afirmar lo contrario, puede hacer parte de un discurso artificioso que busca blanquear la imagen del capitalismo, y que además, intenta poner en escena, discursos falaces que se pregonan camuflados con sostenibilidad, responsabilidad social, eco-sostenibilidad, sello verde, eco-eficiencia, etc., cosas, que se están demostrando que no son en la realidad tanto como se teorizan.

Según datos Pulido y Avendaño (2012), publicados en el informativo digital colombiano La silla vacía, en Colombia la minería especializada en oro, está controlado por: La AngloGold Ashanti, Minerales Andinos de Occidente SA, Mineros SA, CG (antes C o n t i n e $\mathrm{n} t$ a 1 Gold), Negocios Mineros SA, Gramalote Colombia Limited y San Lucas Gold. Son cinco grupos de empresas que tienen 778 títulos, que representan el 40 por ciento del total de títulos mineros otorgados en el país para explotación de oro (1953 títulos). Y estos 778 títulos representan 1 millón 116 mil hectáreas, equivalentes al 50 por ciento del total de hectáreas dedicadas a este tipo de explotación (2 millones 237 mil hectáreas). (p. 1).

Estos datos se sustentan en información del Ministerio de Minas a la que tuvo acceso La Silla Vacía, y que fue publicado en versión digital en febrero 25 de 2012.

En el mismo sentido, y en la misma fuente informativa, Rueda (2012), pregunta, si el tema del extractivismo en Colombia es ¿Minería o robo? Pues, según él: 
Los datos oficiales del Departamento Administrativo Nacional de Estadísticas, DANE en Colombia, si más del noventa y cinco por ciento de la producción de carbón del país es para exportación ¿cómo debe llamarse a estos exportadores, cuando el $68 \%$ de sus utilidades registradas en las cuentas nacionales del DANE no aparecen en sus declaraciones de renta que presentan a la DIAN? Si los extractores de metales preciosos, principalmente de oro, declaran sólo el 10\% de las utilidades para el pago de impuestos ¿cómo deberíamos llamar entonces a quienes no declaran el 90\% restante de esas utilidades? (Rueda, 2012, p.2-3).

Como si fuera poco, y no siendo conformes con las ganancias efectivas de la producción minera, las multinacionales que monopolizan la explotación, Rueda (2012), pone en evidencia que la actividad minera en Colombia, contrario al discurso del gobierno, y según los cálculos, éstos arrojan claras señales de alerta, porque según él:

Carbón y metales preciosos liquidan menos del 25 por ciento sobre las utilidades declaradas, especialmente como resultado de aplicar deducciones por inversiones en activos fijos que autorizaba la ley tributaria. (Rueda, 2012, p.2-3).

Es decir, la cuestión a las claras evidencia el negocio perfecto puesto que garantiza ganancias por partida doble. Basados en estos datos de Rueda (2102), por ejemplo, "carbón y metales preciosos liquidan menos del 25 por ciento sobre las utilidades declaradas, especialmente como resultado de aplicar deducciones por inversiones en activos fijos que autorizaba la ley tributaria." (p. 2-3).

La conclusión hasta ahora es clara: el negocio de la minería anclado en el dispositivo colonial ejerce su influjo hegemónico sobre la geopolítica, y se hace a sí mismo doblemente rentable porque de acuerdo con los análisis de los datos expuestos anteriormente, hay ganancias por ingresos, ganancias por evasión de impuestos y ganancias por pago de tasas bajas de impuestos en razón de las políticas de concesión y laxitud del estado colombiano con el extractivismo a gran escala.

Aclaremos esto desde el análisis y desde los datos de Rueda (2102):

En el período 2002-2010 el sector dejó de pagar, en sólo exenciones y evasiones al impuesto sobre la renta, un valor muy superior a lo que pagó por regalías. La razón, según Rueda (2102), al contrastar los impuestos que resultarian de aplicar las tasas nominales a las utilidades del sector (reportadas por el DANE), con los impuestos declarados por las empresas (en sus declaraciones a la DIAN), se encuentra que difieren en un monto equivalente a un 137 por ciento del total de las regalías percibidas por el Estado por la explotación de estos recursos. (Rueda, 2012, p.2-3).

Adicionalmente, León (2011) analiza que ya hay evidencia de que los narcotraficantes compran oro en Nariño, que no es un lugar minero por excelencia, y lo llevan por la puerta de atrás hasta Antioquia, donde tienen un título minero de una mina improductiva o no tan productiva y lo hacen pasar como si lo hubieran sacado de alli. Denuncia León (2012) que Ingeominas no tiene ninguna forma de saber realmente cuánto es la producción por mina y entonces le cree al dueño de la licencia lo que diga. Según ella, con ese oro estas personas van al Banco de la República o a unas comercializadoras internacionales en Medellín. Allí lo venden y su dinero queda blanqueado en minutos. ${ }^{3}$ 
La colonización de la naturaleza y el fortalecimiento del extractivismo.

Desde la conquista española hasta nuestros días, la situación no ha cambiado. El dispositivo de poder colonial hegemónico ha actuado de la misma manera. Impone su dominio para usufructuar los bienes territoriales, ambientales y ecológicos de las comunidades sometidas. Y opera sobre la base de un estado sumiso y complaciente. Un estado indolente con las minorias étnicas, con el campesinado y con del desarrollo comunitario. Más información puede ampliarse en Vasco (1996), Restrepo (1895), Arango (1965), Gudinas (2009, 2010), Schuldt y Acosta (2009), Bebbington (2009), Monge, et al., (2011).

La economía de América Latina desde el comienzo de la conquista fue influenciada por el modelo mercantilista europeo. La explotación de minerales, de materias primas como la madera, el caucho y la sal, fueron ajustadas a regímenes tributarios. Aunque la agricultura era de subsistencia entre los indios, con la llegada del conquistador se le orientó y tomó vocación de comercio exterior. El intercambio y el trueque entre comunidades locales se transformaron en exportación e importación de mercancías. El mercado interno incipiente entre comunidades indígenas terminó ampliándose para suplir las demandas del comercio externo. De tal modo que antes que fortalecer lazos comerciales internos, el poder hegemónico planteó un desarrollo económico y social a la europea, y como las materias primas estaban en los territorios que fueron colonizados, se requirió la construcción de vías, puertos, infraestructura, políticas y mecanismos comerciales.

Según Bethell (1991), "el modelo de producción español para el siglo XVIII evidenciaba crisis, y había déficit en la producción de alimentos durante los reinados de Carlos III (1759-1788), y Carlos IV (1788-1808)" (p. 1-40). Para resolver el problema de abastecimiento y a la vez, mejorar la economía, que entre otras cosas dependía de lo que se enviaba de los territorios colonizados, "se hizo énfasis en el mercantilismo, para justificar una explotación más eficaz de las riquezas de los pueblos colonizados. También se enfatizó en el liberalismo económico para erradicar las restricciones comerciales e industriales" (Bethell, 1991, p.1-40). Además, según la misma fuente, durante ese período de la historia, se impuso a los pequeños productores condiciones para aumentar la producción de alimentos, por parte de los propietarios - sobre todo miembros de la nobleza y del clero-, que querían maximalizar sus ingresos, y los exportadores, que buscaban nuevos mercados. Para este propósito, la corona española encargó a Manuel Godoy, cortesano enviado por Carlos IV para buscar soluciones a la crisis económica y de credibilidad que enfrentaba la monarquía del momento. Bethell (1991), afirma que Godoy trató a América como si fuera exclusivamente una fuente proveedora de metales preciosos y a sus gentes como simples contribuyentes (p. 1-40). Se comprende entonces que su gestión fue una ficha clave en la recuperación económica de la corona. Entre los propósitos comerciales de la gestión de Godoy, se hizo patente el interés de la empresa colonizadora por establecer el extractivismo. Esto se confirma porque, según Bethell (1991):

España, en ningún momento se constituyo en un proveedor-sustento industrial ni socio comercial para América Latina. Simplemente impuso una economía de extracción para sostener sus requerimientos y demandas. De tal manera que se puede entender que el crecimiento de España como sociedad era por sus características, proporcional al empobrecimiento de América Latina. (Bethell. 1991, p. 1-40). 
A igual que en las postrimerias de la época colonial, en la cartografia económica y social, había grupos de pseudo-élites que heredaban el poder, y mantenian relaciones de clientelismo y de control sobre el pueblo. Además, había pequeños grupos de poder que competían con el poder del estado, estas élites de poder desencadenaron en el caciquismo que es un rasgo de la colonilidad del poder. Y curiosamente, la fuente que sostuvo y nutrió este dispositivo fueron en gran medida las riquezas naturales, el latifundismo, la ganadería extensiva y el caciquismo político.

Vale la pena recordar que fue el deseo de explotación de los recursos-bienes naturales, lo que hizo que en 1534, Sebastián de Belalcazar, que en ese momento se encontraba en Quito, encendiera en frenética ambición de oro al escuchar de un indio el relato de la leyenda famosa del "Dorado". Por esa razón llegó a estas tierras. Y desde entonces se encendió una fiebre por el oro del Dorado. Esa misma fiebre de oro fue la que motivó los múltiples intentos de desagüe de la laguna de Guatavita, la laguna sagrada donde se entronizaban los Caciques Moscas o Muiscas en la tradición ritual de estas "gentes". Según narra Fray Pedro Simón y también Restrepo (1895), Lázaro Fonte, militar de las huestes españolas en tierras muiscas, Hernán Pérez de Quesada, hermano del general conquistador de estas tierras, y Alonso de Sepúlveda (Simón, p. 170-175), y posteriormente José Ignacio Paris en 1823; después un tal Martos, luego los señores Tovar en 1856, y finalmente Crowther y Enrique Urdaneta en 1870 (Restrepo 1895 p. 82-83), intentaron de forma infructuosa vaciar la laguna para extractar el oro. Hoy quienes visitan el lugar pueden observar el gran boquete que dejaron las empresas extractivas de aquél tiempo. Pues se creía y todavía se cree, que en el lecho de la laguna hay incalculables e invaluables piezas del precioso metal. El oro de estas tierras, representa el último tesoro natural, el mismo que según Vasco (1996), ha significado una lucha (sangrienta y bárbara) "por las siete llaves" (p. 237).

El dispositivo colonial que se sustentó en gran parte en el extractivismo, generó lo que Magnus Möerner (1971) denomina la "pigmentocracia". En el sentido en el que toda conquista, siempre hay un poder que subordina a un "otro". Hay siempre un vencedor, alguien que tiene la ventaja, y por tanto, hace valer su poder de conquistador sobre la condición de conquistado. La estructura social colonial se estructuró sobre la diferencia étnica. Y esa diferencia permitió una política de usurpación de la los derechos que el nativo tenía sobre la geografia, sobre la tierra, sobre los recursos-bienes naturales que por hábitat le correspondian. El derecho al hábitat y al usufructo de las riquezas naturales fue cercenado por el modelo económico impuesto por el dispositivo colonial. Destaca Vasco (1984, p. 260263) que "el plan de gobierno del presidente Guillermo León Valencia Muñoz", payanés quien gobernó a Colombia entre los años 1962-1966, era efectivamente "romper las siete llaves" para acceder a las riquezas en manos de los "indios" quienes las mantienian "encerradas en sus territorios", pero que "había que abrirlas para el provecho de la nación". La forma de abrirlas desde entonces ha sido la misma: violencia, desplazamiento, vulneración, y concesión de derechos de explotación y usufructo a los capitales multinacionales.

De otra parte, llama la atención que en Colombia, la inauguración de la Constitución Política de 1991, "constitución verde" llamada por muchos, que en su momento abrió un debate en torno a la condición de las minorias étnicas y las comunidades afros, fue casi inmediatamente instrumentalizada por el poder del turno para ponerla al servicio de lo que desde la década de los noventa se ha denominado la política de la apertura económica. Apertura que paradójicamente ha abierto las puertas al capital que se ha beneficiado de las concesiones del estados, y ha cerrado las posibilidades de desarrollo social para la población rural y campesina, la cual como se observa en los informes de desarrollo humano, desde el 
año 2001, los indicadores de desarrollo humano para la población colombiana, siguen sin mejorar. Para ilustrar un ejemplo. Los informes de PBI Colombia (2011) hablan de que el 60\% de la población afrodescendiente que habita la región del Pacífico no tienen garantizado su derecho a la tierra por vivir fuera de los territorios reconocidos por el Gobierno. En la misma fuente, se afirma que:

De acuerdo con las organizaciones indígenas y afrocolombianas, la violación de los derechos humanos sufridas por estos grupos étnicos se ha concentrado en territorios atravesados por megaproyectos de explotación de hidrocarburos, hay datos que señalan que el 89\% de los indígenas y el $90 \%$ de los afrodescendientes asesinados proceden de áreas mineroenergéticas. (PDI Colombia, p. 17-18).

Esta misma situación, Montero (2012) la denomina "bacriminalización" del conflicto colombiano, la cual es solo la punta del Iceberg de una cuestión compleja que involucra intereses sobre los recursos-bienes naturales del país. Un conflicto que cada vez está mostrando evidencias de su maridaje con el extractivismo y sobre todo con la minería ilegal, la cual, se constituye en el crimen perfecto en la medida en que, como afirma Montero (2012), "no existe una claridad a la hora de diseñar estrategias para contener el tráfico de minerales "negros" como el Coltan, el Tantalio o el Titanio, porque estos se encuentran justamente donde existe una menor presencia estatal, es decir, en las selvas del sur oriente del país" (p. 4).

\section{Conclusiones.}

Discursos progresistas como los de César Gaviria Trujillo, presidente de Colombia de 1990 a1994 y Juan Manuel Santos Calderón, el presidente actual, facilitan el camino a las multinacionales en su intento por apoderarse del país. Según PDI Colombia (2011):

Hasta el 2002 las políticas estatales fueron relativamente conservadoras en términos de la concesión de títulos mineros, pero a partir de ese año comenzaron a incrementarse las solicitudes y concesiones. Entre 1990 y 2001 se entregaron en Colombia 1.889 t it u 1 o s mineros (157 por año) y en 2010 ya había 8.928 concesiones (4.839.149 hectáreas) y 20.000 solicitudes en trámite. (PDI Colombia, 2011, p. 4).

De acuerdo a estos datos, Colombia ha venido cediendo terreno ante los interese del extractivismo. Tanto así, que de acuerdo a la misma fuente informativa, "114 millones hectáreas que componen el extenso y próspero territorio colombiano, más de 8,4 millones están concesionados para la exploración de minerales y más de 37 millones de hectáreas están titulados para la exploración de hidrocarburos". (PDI Colombia, 2011, p. 4).

Este panorama muestra el proceso de colonización de la naturaleza y el fortalecimiento del extractivismo. Por ejemplo:

En 2005 la producción de carbón era de 40 millones de toneladas, en la actualidad es de 72 millones y se estima que para el 2019 se llegue a la producción de 145 millones de toneladas (PDI Colombia, 2011, p. 5). Hay también en este mismo período de tiempo, un aumento en el precio bruto de los minerales. Oro y carbón los más dinámicos. De acuerdo con los datos obtenidos por PDI Colombia (2011), el carbón pasó de 90 dólares en 2004 a casi 160 en 2011 y la onza de oro aumentó su valor de 700 dólares en 2008 a los 1.800 en que se cotiza actualmente. (PDI Colombia, 2011, p. 5). 
En las cifras, Colombia es el primer productor de carbón en América Latina y el décimo en el mundo. La pregunta sigue abierta, ¿A dónde se van todas las ganancias provenientes del extractivismo? ¿Qué sucede con las regalías? ¿Hay desarrollo y bienestar social en las comunidades donde se explota los minerales a gran escala en Colombia?.

Se concluye de este análisis que el extractivismo hace parte del dispositivo colonial que ha dejado como legado en Colombia, élites sociales que dominan el poder, minorias étnicas excluidas de los planes de desarrollo del Estado, formas económicas que rayan con la ilegalidad toda vez que aprovechan la laxitud y la negligencia del estado. La naturaleza fu colonizada para domeñarla y extractarle sus riquezas. Y es en razón de este propósito como el extractivismo desde sus inicios juega un papel importante en el dispositivo de poder colonial. La realidad de las cosas no ha cambiado mucho si se analiza desde este espectro. Más aún, el gobierno Colombino de turno, montado en un discurso abiertamente progresista, no está interesado en hacerle frete al extractivismo. Por el contrario, lo está mostrando como una de las locomotoras para lograr el desarrollo y la prosperidad económica. 


\section{Referencias.}

A., A., \& E., G. (2011). Transiciones postextractivismo y alternativas al extrativismo en el Peru. Obtenido de http://www.redge.org.pe/transiciones-alternativasvariosautores.

Arango C, J. (1981). Revaluacion de las antiguas culturas aborigenes de colombia. Bogota: Plaza y Janes.

Arango C, J. (1989). Mitologia en America precolombiana. Azteca, Chibchas e Incas. Bogota: Plaza y Janes.

Beltran P., F. (1976). La Cosmovisión de los Muiscas. Análisis: publicación semestral de investigación e información.

Bethell, L. (1991). Los origenes de la independencia hispanoamericana. Barcelona: Critica S.A.

Bohorquez, L. (2006). Huella ecologica y habitos de consumo. El reto de la bioetica frente al medio ambiente. Obtenido de publicaciones.lasalle:

http://publicaciones.lasalle.edu.co/images /

openacces/Revistas/usalle/salle42.pdf.

Bohorquez, L. A. (2007). Biopolitica, ambiente y ecologia. Tres temas urgentes para la universidad. revista Management.

Bohorquez, L. A. (junio de 2007). La crisis del agua y desarrollo humano. Obtenido de usbbog: http: / /www.usbbog.edu.co/Nuestra_Universidad/Publicaciones / Management / Management28 / M28_art8.pdf.

Bohorquez, L. A. (2009). Concepcion sagrada de la naturaleza en la mitica muisca. Revista Franciscanum.

Boof, L. (1996). Ecologia, grito de la tierra, grito de los pobres. Mexico D.F: Ediciones Dabar.

Castro Gomez, S. (1998). Geografias poscoloniales y translocalizaciones narrativas de "lo latinoamericano" La critica al colonialismo en tiempos de la globalizacion. Caracas: Editorial Sentido.

Correa R., F. (2005). El Sol del Poder. Simbología y politica entre los muiscas del norte de los Andes. Bogota: Universidad Nacional de Colombia.

De Certeau, M. (1996). La invencion de lo cotidiano. I. Artes de hacer. Mexico D.F.: Universidad Iberoamericana.

Defensoria del pueblo colombiano. (2010). Mineria de hecho en colombia. Bogota: Imprenta Nacional de colombia.

Eliade, M. (1973). Mito y Realidad. Madrid: Ediciones Guadarrama.

Eliade, M. (1996). Lo sagrado y lo profano. Bogota: Editorial Labor S.A. 
Escobar, A. (2005). Mas alla del tercer mundo. Bogota: ICAHN.

Gomez Londoño, A. M. (2005). Muiscas, Representaciones, cartografias, y etnopolítica de la memoria. Bogota: Editorial Pontificia Universidad Javeriana.

Gonzalez, E. (2008). Educacion, medio ambiente y sustentabilidad. Mexico D.F.: Siglo XXI Editores.

Gorbachov, M. (2003). Carta a la tierra. Barcelona: Ediciones del Broce.

Gudynas, E. (2009). Diez tesis urgentes sobre el nuevo extractivismo. Contexto y demandas bajo el progresismo sudamericano actual. Obtenido de Extractivismo, politica y sociedad: http://www.extractivismo.com/noticias/extractivismoquito09.html.

Guhl, E. (1982). Los paramos circundantes de la sabana de bogota. Bogota: Jardin Botanico "Jose Celestino Mutis".

Hernandez Rodriguez, G. (1975). De los Chibchas a la Colonia y a la República (del Clan a la Encomienda y al Latifundio en Colombia). . Bogota: Instituco colombiano de cultura.

Hernandez, R. (1991). Metodologia de la investigacion . Bogota: MacGraw Hill Interamericana.

Jimenez de Quesada, G. (1547). Epitome de la conquista del nuevo reino de granada. Sevilla: Escuela de estudios Hispanos-Americanos.

Krickeberg, W. (1995). Mitos y leyendas de los Aztecas, Incas, Mayas y Muiscas. Mexico D.F.: Fondo de cultura economica.

Lefebvre, H. (1984). La vida cotidiana en el mundo moderno. Madrid: Alianza editorial.

Leff, E. (2004). Racionalidad ambiental. La reapropiación social de la naturaleza. Mexico D.F.: Siglo XXI Editores.

Leon, J. (2011). La llanada, la tercera via en mineria. Obtenido de La silla vacia: http://www.lasillavacia.com/historia/la-llanada-la-tercera-en-mineria- 22654.

Levi Strauss, C. (1982). El pensamiento salvaje. Mexico D.F.: Fondo de Cultura economica .

Lovelock, J. (2011). La tierra se agota. Barcelona: Pllaneta.

Mignollo, W. (2003). Historias locales, diseños globales. Madrid: Akal.

Monge , C. (2011). Extractivismo y transiciones hacia el postextractivismo en el Peru. Obtenido de Transiciones postextractivismo y alternativas al extractivismo en el peru: http://www.redge.org.pe/transiciones-alternativas-variosautores.

Montero, L., \& Moncada , A. (2012). Mineria en colombia. Un frente de guerra que se abre. Obtenido de de: http://www.iegap-unimilitar.edu.co/ images/docs/ analpolitmineriailegal.pdf. 
Montoya, J. (1973). Antología de creencias, mitos, teogonías, cosmogonías, leyendas y tradiciones de algunos grupos aborígenes colombianos. Bogota : Imprenta municipal.

Morin, E. (2005). Tierra patria. Barcelona: Kairós.

Mörner, M. (1971). Le Métissage dans I'histoire de I'Amérique latine. Paris: Fayard.

Naciones Unidas . (2009). Informe sobre desarrollo humano .

Naciones Unidas . (2010). Informe sobre desarrollo humano .

Naciones Unidas . (2011). Informe sobre desarrollo humano .

Naciones Unidas. (2006). Informe sobre desarrollo humano.

Naciones Unidas. (2007). Informe sobre desarrollo humano .

Naciones Unidas. (2007). Informe sobre objetivos del milenio.

Naciones Unidas. (2008). Informe sobre desarrollo humano .

PBI. (2011). Mineria en colombia ¿A que precio? Obtenido de http://www.pbicolombia.org/field-projects/pbi-colombia/publications/.

PBI. (2011). Mineria en colombia: ¿A que precio? Obtenido de http://www.pbicolombia.org/fileadmin/user_files/projects/colombia/files/colomPBIa/111122_bo letin_final_web.pdf.

Piedrahita, L. (1973). Noticia historial de las conquistas del Nuevo Reino de Granada. Cali: Carvajal.

Portal de informacion minera an colombia. (2012). Obtenido de www.imcportal.com/index.php.

Pulido, A., \& Avendaño, C. (2012). ¿A quien le pertenece el oro en colombia? Obtenido de La silla vacia: http://www.lasillavacia.com/historia/quien-le- pertenece-el-oro-encolombia-30930.

Rawl, J. (1985). Teoria de la justicia. Mexico D.F.: Fondo de cultura economica.

Reichel Dolmatoff, G. (1997). Arqueologia de Colombia. Un texto Introductorio. Bogota: Presidencia de la republica.

Restrepo, V. (1985). Los chibchas antes de la conquista. Bogota: Imprenta de la luz.

Ricoeur, P. (2000). Del texto a la accion. Buenos Aires : Fondo de cultura economica.

Ricoeur, P. (2003). El conflicto de las interpretanciones.Ensayos de hermeneutica. Buenos Aires: Fondo de cultura economica. 
Riechmann, J. (2005). Biomímesis. Ensayos sobre imitación de la naturaleza. Eco socialismo y auto contención. Madrid: Catarata.

Riechmenn, J. (2006). Un mundo vulnerable. Ensayos sobre ecologia, etica y tecnociencia. Madrid: Catarata.

Rodriguez Freire, J. (1963). El carnero. Bogota: Imprenta Nacional.

Rozo G., J. (1997). Mito y rito entre los muiscas. Bogota: El Buho.

Rudas, G. (2012). ¿Mineria o robo? En la silla vacia. Obtenido de http://www.lasillavacia.com/elblogueo/grudas/31076/mineria-o-robo.

Ruedas, G. (2012). La locomotora minera a toda marcha ¿Pero paga lo que debe? Obtenido de Razonpublica: http://www.razonpublica.com/index.php/econom-y- sociedadtemas-29/2691-1a-locomotora-minera-a-toda-marcha-ipero- paga-lo-quedebe.html

Schuldt, J., \& Acosta, A. (2009). Petroleo, rentismo y subdesarrollo ¿Una maldicion sin solucion? Obtenido de Extractivismo, politica y sociedad: http://www.extractivismo.com/noticias/extractivismoquito09.html.

Silva C., E. (1968). Arqueología y prehistoria de Colombia. Tunja: Universidad Pedagogica y tecnologica de colombia.

Silva C., E. (2005). Estudio sobre la cultura Chibca. Tunja: Academica Boyacense de Historia.

Simon, F. P. (1981). Noticias historiales de las conquistas de Tierra Firme en las Indias Occidentales. Bogota: Biblioteca de autores colombianos.

Triana, M. (1922). La civilizacion chibcha. Bogota: Escuela tipografica Salesiana.

Van Der Hammen, T. (1992). Historia, ecologia y vegetacion. Bogota: Fondo FEN de Colombia, el fondo de promocion de Cultura del Banco Popular y COA.

Vasco, L. G. (1996). La lucha por las siete llaves, las minorias étnicas en Colombia. Bogota: Ecoe Ediciones .

Zerda, L. (1883). El dorado. Estudio historico, etnografico y arqueologico de los chibchas. Bogota: Sociedad de ciencia sociales y medicina. 
${ }^{2}$ Según Bohórquez (2008), citando a Eliade (1961) y a Rozo (1997), "la Historia mítica son todas las construcciones de ideas, las representaciones culturales, que se vuelven celebrativas... es la codificación y estructuración mental y pragmática de todas las cosas, fenómenos y acciones de la naturaleza. De la historia mítica surgen los relatos sociales y politicos. La historia mítica ordena los elementos sociales que separan y asocian naturaleza, cultura y pensamiento"(p. 22-23).

3 Más información en: http://www.lasillavacia.com/historia/la-1lanada-la-tercera-enmineria-22654 (actualizado junio de 2012). 